\title{
BDA Update
}

1 Anesthesia in Dentistry and Complications, Legal Considerations, Questions, and the Future. However, two completely new chapters have been introduced into the final section of the book. The new Chapter 19 covering problems in achieving pain control has been added because one of the author's most frequently asked questions is about how to consistently achieve effective pulpal anaesthesia with teeth that are acutely pulpally involved. In the new Chapter 20, Malamed explores five fairly new additions to 'the pain control armamentarium in dentistry' that he feels will stand the test of time. This book can be purchased for the library's ebook collection on request.

\section{View from my window}

Duncan Parker-Groves sent this view from his dental surgery.

Duncan writes: 'I am currently serving as part of an exchange programme in Brunei Darussalam, the Abode of Peace, alongside the RBAF as a dental officer.

'This is the fantastic view from my dental surgery at the Berakas Kem (RBAF land forces camp). I am fortunate to look out over the golf course and I am frequently visited at my window by wild boars and macaque monkeys. The monkeys take a particular interest in extractions! If you look carefully you can see a monkey walking off.'

If you would like to send the view from your practice window, please email k.quinlan@nature.com.

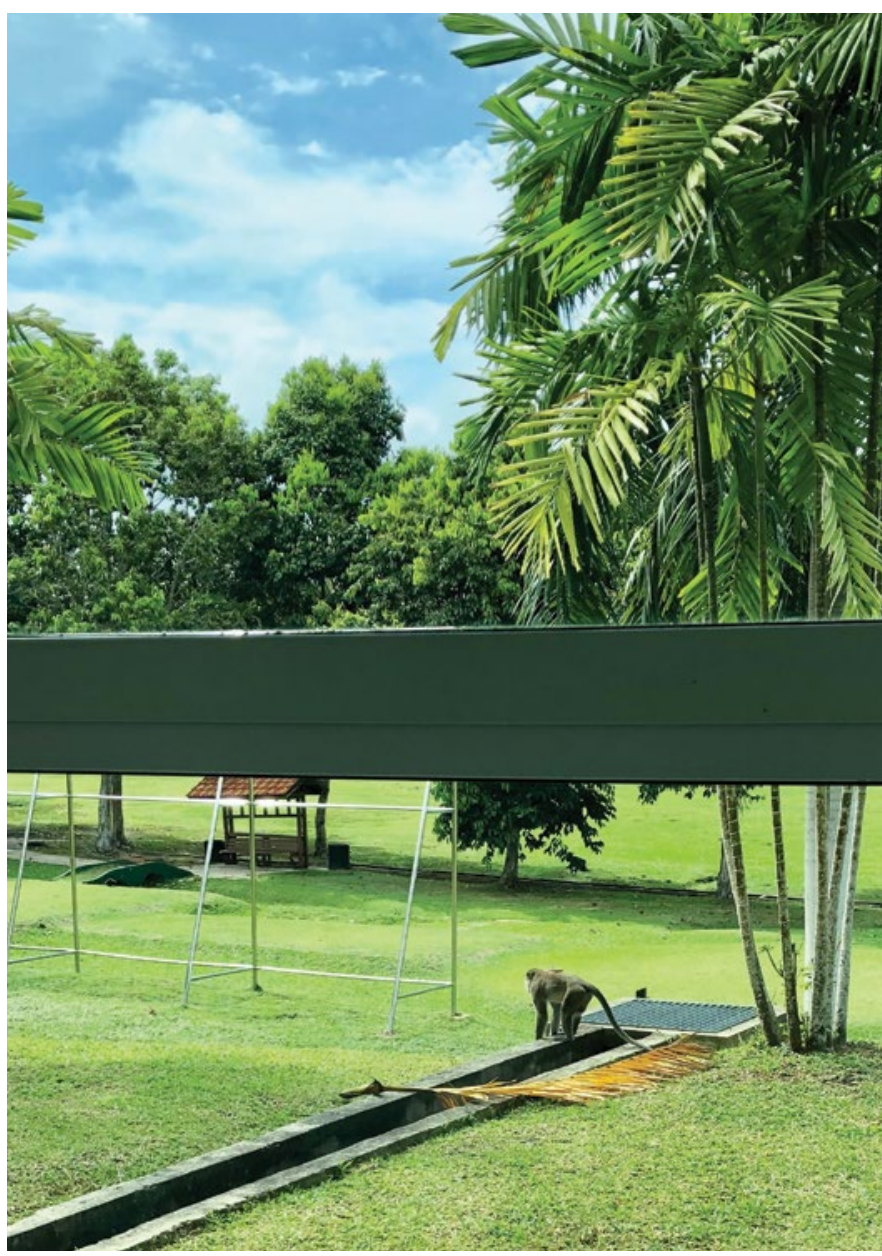

\section{Apps no quick fix}

The BDA has expressed scepticism over the role of teleconsultations in dentistry, following the launch of the new app Tooth Fairy.

The BDA recognises the potential for this technology in areas including triaging cases for NHS 111, but does not see how it is possible to conduct a full and thorough examination remotely on the basis of current technology.

\section{Oral surgery scandal}

BDA Scotland has said government must take responsibility and tackle waiting times of over two years for oral surgery.

Freedom of Information requests undertaken by the Scottish Liberal Democrats have revealed waits of over 120 weeks (2.3 years) for inpatient oral and maxillofacial treatment, covering diseases affecting the mouth, jaw, face and neck - with one patient in the NHS Grampian area having waited 243 weeks (4.6 years) for an outpatient procedure. The Scottish Government operates a 12 -week target for surgery.

These figures include procedures that can restore the functionality and appearance of a patient's mouth following oral cancer - which ranks among Scotland's fastest growing cancers - or serious injury.

There have been huge problems filling consultant vacancies and continued underfunding of both primary and secondary dental services.

\section{Delayed pay rise}

In October the BDA received confirmation that dentists will get a $2.42 \%$ uplift in their November pay run. The Department of Health and Social Care (DHSC) and HM Treasure calculated the formula using the consumer price index for inflation, not the retail price index for inflation, as argued by the BDA.

The DHSC confirmed that the uplift for 2019/2020 will be backdated to April 2019. The BDA questions why implementing the dentists' award continues to lag so many months behind, when practitioners are obliged to pay their bills in a timely fashion.

\section{Are you a dental expert?}

The dental expert plays a pivotal role and is essential to the defence of a dental colleague faced, for example, with a GDC fitness to practise hearing or who finds themselves subject to a claim in negligence.

BDA Indemnity is now looking to expand the dental experts that they can call on, covering the whole spectrum of dental practice, to help the rapidly growing number of BDA Indemnity members that have been joining since our inception date of 3 June 2019.

We are looking for experts who have current experience of doing this type of work, with knowledge of expert report writing and being prepared potentially for cross examination in court procedures.

If you are interested in this unique opportunity to work in this niche area of dentistry to help your professional colleagues, then please send in your current $\mathrm{CV}$ on a confidential basis by the closing date of 31 December 2019 to be considered for this vital role for BDA Indemnity members. Please send to bda.indemnity@bda.org. 